$$
\text { Conf }-951013--2
$$

UCRL-JC- 120969

PREPRINT

\title{
Constraints on Elastic Parameters and Implications for Lithology on VTI Media
}

\author{
P.A. Berge
}

This paper was prepared for submittal to

Society of Exploration Geophysicists International Expo and 65th Annual Meeting Houston, Texas, October 8-13, 1995

June 2, 1995

JUL 181005

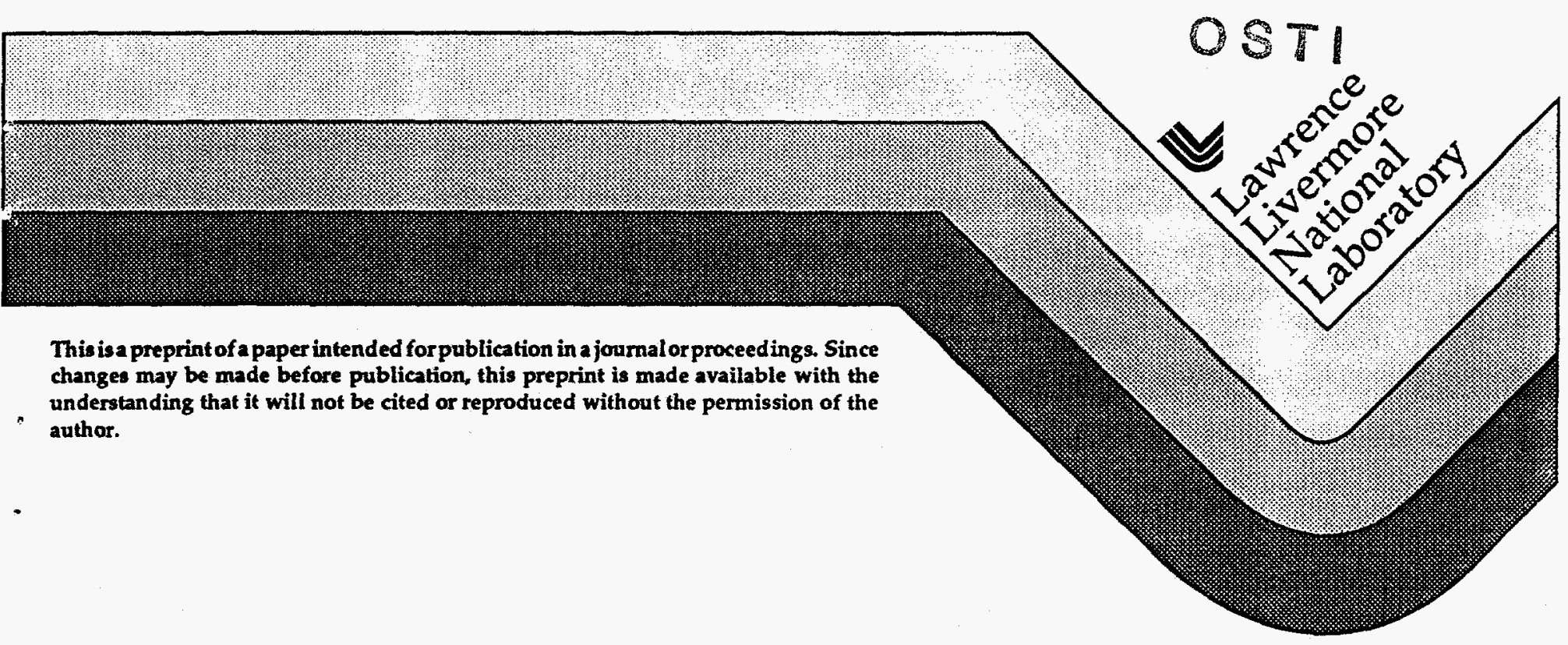




\section{DISCLAIMER}

This report was prepared as an account of work sponsored by an agency of the United States Government. Neither the United States Government nor any agency thereof, nor any of their employees, make any warranty, express or implied, or assumes any legal liability or responsibility for the accuracy, completeness, or usefulness of any information, apparatus, product, or process disclosed, or represents that its use would not infringe privately owned rights. Reference herein to any specific commercial product, process, or service by trade name, trademark, manufacturer, or otherwise does not necessarily constitute or imply its endorsement, recommendation, or favoring by the United States Government or any agency thereof. The views and opinions of authors expressed herein do not necessarily state or reflect those of the United States Government or any agency thereof. 


\section{DISCLAIMER}

Portions of this document may be illegible in electronic image products. Images are produced from the best available original document. 
Constraints on Elastic Parameters and

Implications for Lithology in VTI Media

P. A. Berge, Lawrence Livermore National Laboratory

\section{SUMMARY}

Energy considerations provide constraints on elastic stiffnesses in media exhibiting transverse isotropy with a vertical axis of symmetry. If the anisotropy is due to thin layers, additional constraints hold. The constraints can be used to provide insight into the mechanisms causing the anisotropy, which in turn gives information about the lithology. These jdeas are illustrated by some examples of anisotropic sedimentary rocks and sediments from the literature.

\section{INTRODUCTION}

The elastic properties of a medium exhibiting transverse isotropy with a vertical axis of symmetry (VTI medium) are described by five independent elastic stiffnesses. The stiffnesses $C_{11}, C_{13}, C_{33}$, and $C_{44}$ describe $P$ and $S V$-wave propagation, while $C_{44}$ and $C_{66}$ describe $S H$ waves (Auld, 1973). Requiring positive strain energy in a VTI medium provides the following rigorous constraints on the elastic stiffnesses:

$$
\begin{gathered}
C_{11} \geq C_{66} \geq 0, \\
C_{33} \geq 0, \\
C_{44} \geq 0,
\end{gathered}
$$

and

$$
C_{13}^{2} \leq C_{33}\left(C_{11}-C_{66}\right)
$$

(Auld, 1973). When the anisotropy is caused by thin layering, additional constraints apply:

$$
\begin{aligned}
C_{33} & >C_{13}, \\
C_{33} & >\frac{4}{3} C_{44},
\end{aligned}
$$

and

$$
C_{66} \geq C_{44}
$$

(Backus, 1962). The VTI medium can also be described using vertical ray velocities $V_{P}=\sqrt{C_{33} / \rho}$ and $V_{S V}=\sqrt{C_{44} / \rho}$ (where $\rho$ is the density) together with the parameters $\epsilon, \delta$, and $\gamma$ defined by Thomsen (1986):

$$
\begin{gathered}
\epsilon \equiv \frac{C_{11}-C_{33}}{2 C_{33}} \\
\delta \equiv \frac{\left(C_{13}+C_{44}\right)^{2}-\left(C_{33}-C_{44}\right)^{2}}{2 C_{33}\left(C_{33}-C_{44}\right)}
\end{gathered}
$$

and

$$
\gamma \equiv \frac{C_{66}-C_{44}}{2 C_{44}}
$$

The Thomsen parameters were originally defined for the purpose of quantifying weak anisotropy, but provide convenient notation for describing any VTI medium since the algebraic expressions in (8) through (10) appear in the equations for dip-moveout corrections, normal-moveout velocities, and variations of amplitude with offset for seismic reflection data (e.g., Thomsen, 1986; Berge, 1991; Tsvankin, 1994; Alkhalifah and Tsvankin, 1994; Tsvankin and Thomsen, 1994; Blangy, 1994). The factor $\epsilon-\delta$ is particularly important. The above constraints on elastic stiffnesses translate into constraints on the velocities and the Thomsen parameters. For anisotropy due to thin layers, $V_{P} / V_{S V}>4 / 3$ from (6), and also

$$
\epsilon-\delta \geq 0
$$

(Backus, 1962; Berryman, 1979; Thomsen, 1986). The $P$ waves are elliptical and the $S V$-waves are spherical if $\epsilon=\delta$ (Helbig, 1983; Thomsen, 1986). Thin isotropic layers with constant isotropic Poisson's ratio give $\delta=0$ (Thomsen, 1986). Schwartz et al. (1994) have shown that for models of granular materials and models containing randomlyoriented cracks, applied uniaxial stress induces anisotropy with VTI symmetry and $\epsilon \approx \delta$. These constraints and special cases highlight the physical meaning of the elastic stiffnesses and Thomsen parameters, and can be used to explore constraints on lithology in VTI media.

\section{ESTIMATING ELASTIC STIFFNESSES AND $\epsilon, \delta, \gamma$}

Values of $\epsilon$ and $\delta$ can be estimated from velocity analysis of seismic reflection data (e.g., Thomsen, 1986; Alkhalifah and Tsvankin, 1994; Tsvankin and Thomsen, 1994). $V_{P}$ can be found from check shots or well log data. Then $C_{11}$ and $C_{33}$ can be determined from $\epsilon$ and $V_{P}$. Additional information would be needed to determine both $C_{13}$ and $C_{44}$ from $\delta$ and $C_{33}$.

If no additional information were available, the constraints above at least give an upper bound on $C_{13}$ and a lower bound on $C_{44}$, plus an upper bound on $C_{44}$ if the anisotropy is due to thin layers. For consolidated sedimentary rocks, the usual range for $V_{P} / V_{S V}$ is about 1.5 to 2 . This could be used with $C_{33}$ to approximate $C_{44} C_{41}$ can br

\section{MASTER}


estimated if $V_{S V}$ is known (e.g., from well log data), or if $S V$ or $P-S V$ stacking velocities are available.

The $S H$-wave stacking velocity provides an estimate of $\gamma$, which can be used to find $C_{66}$. Although $S H$ data are not usually available, the constraints above give upper and lower bounds for $C_{66}$. In the case of elliptical anisotropy, with $\epsilon-\delta=0,(4)$ and (8)-(10) can be used to show that

$$
\epsilon-\gamma \geq \frac{C_{33}-2 C_{13}}{2 C_{33}} .
$$

\section{IMPORTANCE OF $\mathrm{C}_{13}$ AND $\delta$}

The value of $C_{13}$ controls the $P$ - and $S V$-wave velocities at ray angles intermediate between the horizontal and vertical directions. In an isotropic medium, $C_{13}=$ $C_{33}-2 C_{44}$. But in a VTI medium, it is possible to have a large $C_{13}$ with

$$
C_{13}>C_{33}-2 C_{44},
$$

or alternatively a small $C_{13}$ with

$$
C_{13}<C_{33}-2 C_{44} .
$$

A VTI medium with a small $C_{13}$ value has slower $P$-wave velocities and faster $S V$-wave velocities at intermediate ray angles than an isotropic medium would have. A VTI medium with a large $C_{13}$ value has faster $P$-wave velocities and slower $S V$-wave velocities at intermediate ray angles than an isotropic medium would have. $C_{13}$ affects the amplitudes as well as the velocities since it controls the partitioning of energy.

It is always true that $\delta=0$ when $C_{13}=C_{33}-2 C_{44}$. These conditions describe isotropic media, and also VTI media where the anisotropy is due to thin layers with constant Poisson's ratio.

For the case of large $C_{13}$ in (13), $\delta>0$ unless $C_{33}<$ $C_{44}$ and $C_{33}>-C_{13}$. From (6), $\delta>0$ for large $C_{13}$ if thin layers cause the anisotropy. Since most rocks have $V_{P}>V_{S V}$ and $C_{33}>C_{44}$, it is usually true that $\delta>0$ when $C_{13}$ is large.

If $C_{13}$ is small as in (14), $\delta<0$ unless $C_{33}>C_{44}$ and $-C_{33}>C_{13}$. Negative values of $C_{13}$ may not be very common, which implies that usually $\delta<0$ when $C_{13}$ is sinall.

\section{EXAMPLES}

Table 1 gives the values of the elastic stiffnesses and the Thomsen parameters for some typical VTI sedimentary rocks and sediments. Velocity surfaces showing wavefront shapes in the sagittal plane are plotted in Figure 1 for these VTI media. The sedimentary rocks in Table 1 were described by Thomsen (1986). The marine silty clay properties were determined in an ocean-bottom refaction experiment in unconsolidated sediments, as described by Berge et al. (1991).

Note that the only rocks and sediments having nonnegative values of $\epsilon-\delta$ in Table 1 are the Dog Creek shale, Taylor sandstone, and the marine silty clay. The anisotropy in these rocks and sediments may be due to thin layers, but none of the other rocks can have anisotropy due to thin layers. If thin isotropic layers cause the anisotropy in the marine silty clay and the Taylor sandstone, the Poisson's ratios of the isotropic components do not vary greatly, since $\delta$ is close to 0 in these materials.

The Berea sandstone, Pierre shale, and marine silty clay all have $\epsilon-\delta \approx 0$, indicating that it is possible the anisotropy in these rocks and sediments is caused by application of vertical stress. That cannot be the case for any of the other rocks in Table 1.

The Cotton Valley shale and Mesaverde mudshale have large values of $C_{13}$ as described by the inequality in (13). The wavefronts for these rocks are similar, showing a decrease in the $S V$-wave velocities as the ray angle increases from 0 to intermediate angles (as measured from the Z-axis). As expected, $\delta>0$ for these rocks having large $C_{13}$ values.

The rest of the rocks and sediments in Table 1 have $C_{13}$ values that are fairly close to the isotropic case. The Taylor sandstone and the marine silty clay have slightly small values for $C_{13}$ as described by inequality (14). Note $\delta$ is negative, although very close to 0 . The $S V$-wave velocity has a maximum at intermediate ray angles, as shown in Figure 1. The Pierre shale and the Berea sandstone in Table 1 have $C_{13}$ values that are very close to the value for the isotropic case. These rocks have $\delta \approx 0$, and the $S V$-wave surfaces in Figure 1 are nearly circular in crosssection. The Dog Creek shale has a slightly large value for $C_{13}$, and $\delta$ is positive.

$\begin{array}{lrr}\text { Material } & \begin{array}{r}\mathrm{C}_{11 / \rho} \\ (\mathrm{km} / \mathrm{s})^{2}\end{array} & \begin{array}{r}\mathrm{C}_{13 / \rho} \\ (\mathrm{km} / \mathrm{s})^{2}\end{array} \\ \text { Cotton Valley shale } & 28.31 & 9.58 \\ \text { Mesaverde mudshale } & 21.91 & 9.68 \\ \text { Pierre shale } & 4.99 & 3.25 \\ \text { Berea sandstone } & 17.76 & 3.84 \\ \text { Taylor sandstone } & 13.84 & 4.25 \\ \text { Dog Creek shale } & 5.10 & 2.48 \\ \text { Marine silty clay } & 2.64 & 2.56 \\ & & \\ & \\ \text { *Thomsen (1986); Berge et al..(1991). }\end{array}$

Table 1. Parameters for VTI rocks and sediments.*

\begin{tabular}{|c|c|c|c|c|c|c|}
\hline $\begin{array}{l}\mathrm{C}_{66 / \rho} \\
(\mathrm{km} / \mathrm{s})^{2}\end{array}$ & $\begin{array}{c}V_{P} \\
(\mathrm{~km} / \mathrm{s})\end{array}$ & $\begin{array}{c}\text { VSV } \\
(\mathrm{km} / \mathrm{s})\end{array}$ & E & $\delta$ & $\gamma$ & $\underset{\left(\mathrm{g} / \mathrm{cm}^{3}\right)}{\rho}$ \\
\hline 11.359 & 4.72 & 2.89 & 0.135 & 0.205 & 0.180 & 2.14 \\
\hline & 4.53 & 2.70 & 0.034 & 0.211 & 0.046 & 2.52 \\
\hline 0.995 & 2.20 & 0.97 & 0.015 & 0.060 & 0.030 & 2.25 \\
\hline 7.168 & 4.21 & 2.66 & 0.002 & 0.020 & 0.005 & 2. \\
\hline 5.051 & 3.37 & 1.83 & 0.110 & -0.035 & 0.255 & 2.50 \\
\hline 1.153 & 1.88 & 0.83 & 0.225 & 0.100 & 0.345 & 2.00 \\
\hline 0.033 & 1.62 & 0.16 & $0.0(0)$ & -0.011 & 0.1601 & 211 \\
\hline
\end{tabular}

\begin{tabular}{rr}
$\mathrm{C}_{33} / \rho$ & \multicolumn{1}{c}{$\mathrm{C}_{44 / \rho}$} \\
$(\mathrm{km} / \mathrm{s})^{2}$ & $(\mathrm{~km} / \mathrm{s})^{2}$ \\
22.29 & 8.352 \\
20.51 & 7.306 \\
4.85 & 0.939 \\
17.69 & 7.097 \\
11.34 & 3.345 \\
3.52 & 0.682 \\
2.64 & 0.025
\end{tabular}


All of the rocks and sediments in Table 1 have $C_{11} \approx$ $C_{33}^{\prime}$, except for the Cotton Valley shale, Taylor sandstone, and the Dog Creek shale. $C_{44} \approx C_{66}$ for all but the Cotton Valley shale, Taylor sandstone, Dog Creek shale, and the marine silty clay. The shear wave velocity anisotropy is more significant than the compressional wave velocity anisotropy, for all the rocks and sediments in Table 1. Note that $V_{P} / V_{S V}$ is about 1.6-2.3 for all the rocks, but is much larger for the unconsolidated marine silty clay. For unconsolidated VTI sediments, it may be typical to have $C_{13} \approx C_{11}$ or $C_{33}$ and $C_{44} \ll C_{33}$ or $C_{11}$.

\section{CONCLUSIONS}

The constraints on the elastic stiffnesses provide constraints on the sign of the quantity $\epsilon-\delta$ and the value of $\delta$ that are linked to possible mechanisms causing the anisotropy. This information in turn can guide lithology interpretation for VTI media.

In the examples shown, the anisotropy in the Taylor sandstone and the marine silty clay could be caused by thin layers of isotropic materials with similar Poisson's ratios, such as sand and lithics in the case of the Taylor sandstone and interbedded sand, silt, and clay particles for the marine sediments. The Dog Creek shale anisotropy may also be caused by some subhorizontal layering, but the components have contrasting Poisson's ratios. Possibly this indicates subhorizontal cracks rather than layers.

For the Pierre shale and the Berea sandstone, uniaxial stress such as overburden pressure could cause the anisotropy. The Berea sandstone may behave like a granular model that is isotropic under hydrostatic stress and VTI under uniaxial stress, and the Pierre shale may contain randomly oriented cracks that exhibit anisotropy under uniaxial stress as the horizontal cracks close and vertical cracks dilate.

The Cotton Valley shale and the Mesaverde mudshale have some form of intrinsic anisotropy. Of particular interest in these materials are the large values of $C_{13}$ and $\delta$ and their effects on wavefronts. Note that the physical meaning of $\delta$ can be described in terms of the vertical ray velocity $V_{P}$ and the approximate hyperbolic $P$-wave normal moveout velocity $V_{N M O}$ :

$$
\delta=\frac{V_{N M O}^{2}-V_{P}^{2}}{2 V_{P}^{2}} .
$$

\section{REFERENCES}

Alkhalifah, T.A., and Tsvankin, I., 1994, Velocity analysis for transversely isotropic media: 64th SEG Annual Meeting, Expanded Abstracts, 1000-1003.

Auld, B.A., 1973, Acoustic fields and waves in solids, Vol. 1 and 2, John Wiley \& Sons, Inc., New York.

Backus, G.E., 1962, Long-wave elastic anisotropy produced by horizontal layering: J. Geophys. Res., 67, 4427-4440.
Berge, P.A., 1991, Estimating $S V$-wave stacking velocities for transversely isotropic solids: Geophysics, 56, 1596-1602.

Berge, P.A., Mallick, S., Fryer, G.J., Barstow, N., Carter, J.A., Sutton, G.H., and Ewing, J.I., 1991, Insitu measurement of transverse isotropy in shallow-water marine sediments: Geophys. J. Int., 104, 241-254.

Berryman, J.G., Long-wave elastic anisotropy in transversely isotropic media: Geophysics, 44, 896-917.

Blangy, J.P., 1994, AVO in transversely isotropic media An overview: Geophysics, 59, 775-781.

Helbig, K., 1983, Elliptical anisotropy - Its significance and meaning: Geophysics, 48, 825-832.

Schivartz, L.M., Murphy, III, W.F., and Berryman, J.G., 1994, Stress-induced transverse isotropy in rocks: 64th SEG Annual Meeting, Expanded Abstracts, 1081-1085.

Thomsen, L., 1986, Weak elastic anisotropy: Geophysics, 51, 1954-1966.

Tsvankin, I., 1994, Analytic description of dip moveout in anisotropic media: 64th SEG Annual Meeting, Expanded Abstracts, 1209-1212.

Tsvankin, I., and Thomsen, L., 1994, Nonhyperbolic reflection moveout in anisotropic media: Geophysics, 59, 12901304 .

Figure 1. Ray velocity surfaces for the transverely isotropic rocks and sediments listed in Table 1. Cross sections of ray velocity surfaces in the sagittal plane show wavefront shapes since ray velocity is proportional to distance a wave travels in unit time. Solid lines indicate the $P$ ray velocity curves; dashed lines show $S V$ and dotted lines show $S H$. (a) Cotton Valley shale. (b) Mesaverde mudshale. (c) Pierre shale. (d) Berea sandstone. (e) Taylor sandstone. (f) Dog Creek shale. (g) Marine silty clay.

(a) Cotton Valley shale

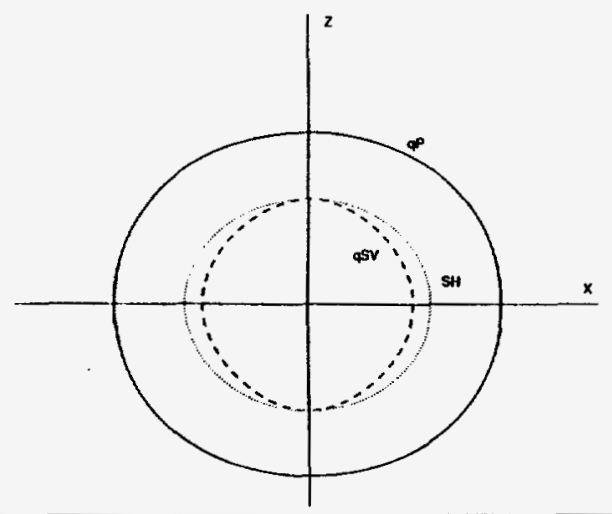




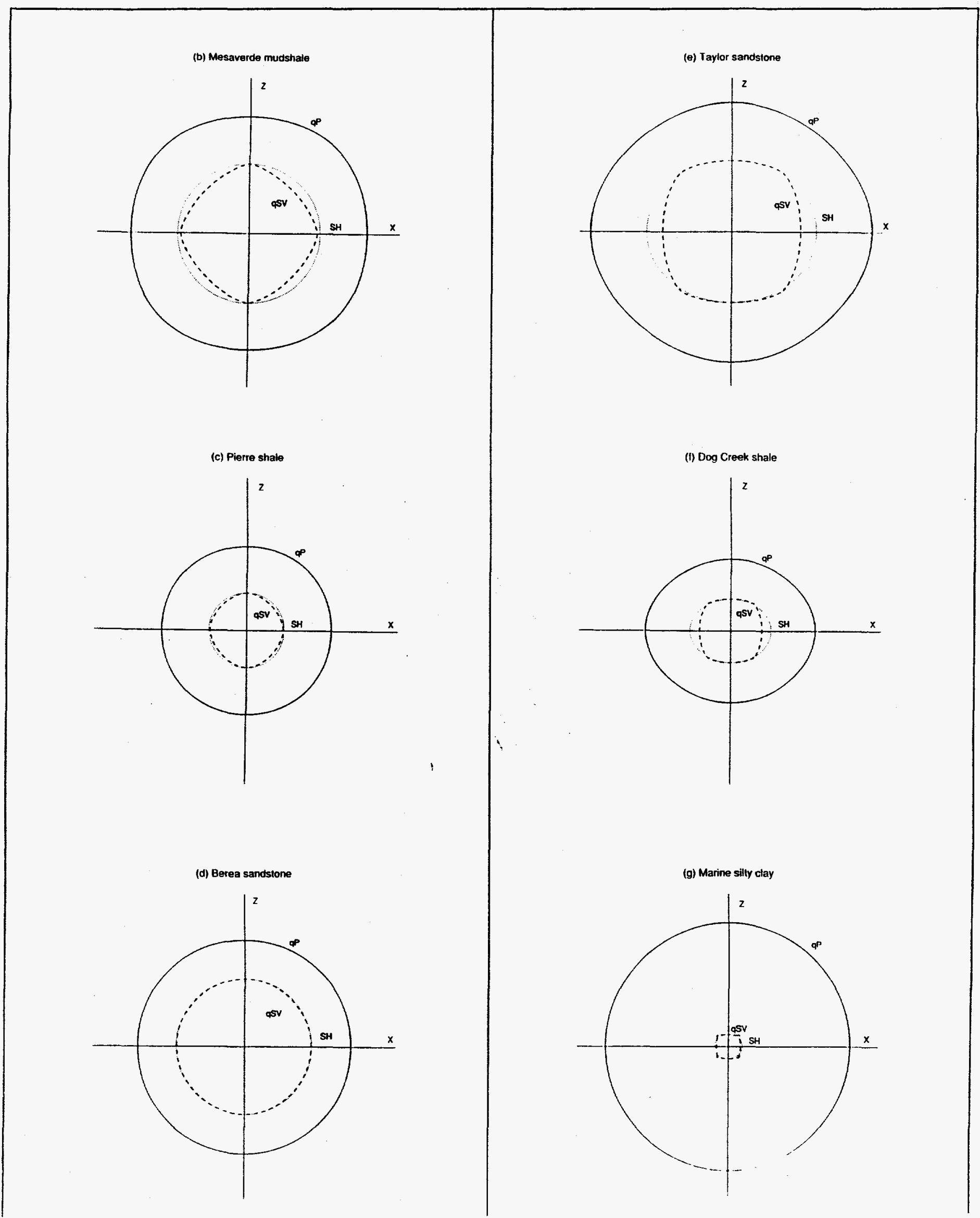

Work performed under the auspices of the U.S. Department of Energy by Lawrence Livermore National Laboratory under Contract W-7405-ENG-48. 